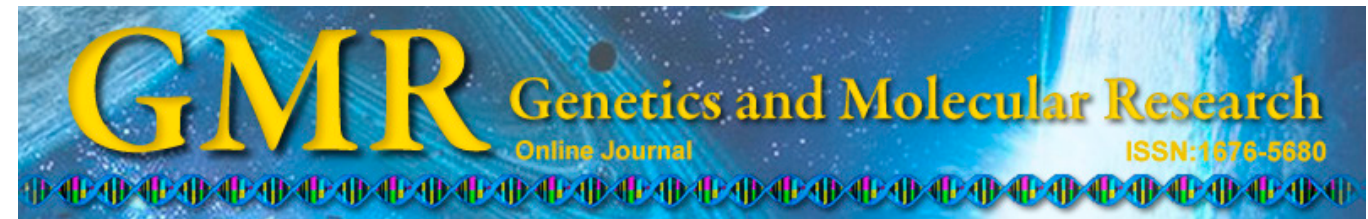

\title{
Proteomic analysis identifies differentially expressed proteins participating in forming Type III brush hair in Yangtze River Delta white goat
}

B. Yang, M.Y. Cai, Y.J. Li, H. Zhang, G.H. Cheng, J.H. Zhang, G.J. Zhang, W.T. Li and D.J. Ji

Key Laboratory for Animal Genetic, Breeding, Reproduction and Molecular Design of Jiangsu Province, College of Animal Science and Technology, Yangzhou University, Yangzhou, Jiangsu, China

Corresponding author: Y.J. Li

E-mail: liyj@yzu.edu.cn

Genet. Mol. Res. 14 (1): 323-338 (2015)

Received June 2, 2014

Accepted October 23, 2014

Published January 23, 2015

DOI http://dx.doi.org/10.4238/2015.January.23.6

ABSTRACT. The Yangtze River Delta white goat is a goat breed that can produce high quality brush hair (Type III hair) around the world. This study aimed to compare Type III hair and non-Type III hair goat skin tissues using differentially expressed proteins based on 2-dimensional gel electrophoresis technology. The differentially expressed protein spots were analyzed using the PDquest 8.0 software. Ten protein spots were detected as positive for mass spectrometric analysis based on a threshold of 2-fold change. Through matching based on Ultraflex III TOF/TOF and MASCOT database, four differentially expressed proteins were identified. Fibrinogen beta chain isoform 1 and ATP synthase beta subunit were upregulated in Type III hair, while succinyl-CoA:3-ketoacid-coenzyme A transferase 1-mitochondrial-like and actin-cytoplasmic 1 were upregulated in non- 
Type III hair. The 4 proteins play important roles in different aspects of hair follicle development. These findings could pave a good foundation for explaining the mechanism of forming Type III hair.

Key words: Yangtze River Delta white goat; Type III brush hair; Two-dimensional gel electrophoresis; Proteomics

\section{INTRODUCTION}

The Yangtze River Delta white goat is a goat breed that can produce high-quality brush hair (namely, Type III hair) around the world. Type III hair is used to make high-grade writing brushes because of its white color, straight hair shaft, long and fine tip, bright luster, and good flexibility (Li et al., 2013). Because of its unique style, writing brushes made of Type III hair win popular praise, together with ink sticks, ink slabs, and rice paper, which are known as "the scholar's four jewels." Chinese calligraphy was listed on the world-class intangible cultural heritage list in 2009. As the source of high-grade writing brushes, Type III hair is valuable. Type III hairs, which are distributed mainly in the cervical carina region and ventral region, are at least $6 \mathrm{~cm}$ long and are commonly, but not always, observed in 6- to 8-month-old male lambs. The key point of Type III hair is the formation of specific hair shafts. Hair shafts are made by the hair follicle, which constitutes the pilosebaceous unit together with its associated structures, the sebaceous gland, the apocrine gland, and the arrector pili muscle (Schneider et al., 2009). The hair follicle is an organ that experiences life-long cycles of anagen, catagen, and telogen. Morphologically, hair follicle cycling does not begin with anagen, but with catagen (Paus and Foitzik, 2004). Telogen is greatly significant in cycling; for instance, estrogen receptors are maximally expressed during telogen (Conrad and Paus, 2004). Anagen development is regulated by many factors. For example, the transforming growth factor- $\beta$ (TGF- $\beta$ )/bone morphogenetic protein (BMP) family members and their functional antagonists and cognate receptors are re-utilized during anagen (Paus and Foitzik, 2004). Hair follicles can metabolize or synthesize growth factors including TGF- $\beta 1 / 2$, hepatocyte growth factor, and insulin-like growth factor 1; neuropeptides; neurotransmitters; and hormones including corticotropin-releasing hormone, prolactin, cortisol, and melatonin (Krause and Foitzik, 2006). Matrix cells can differentiate to form the inner root sheath and hair shaft during anagen. Hair shaft differentiation seems to be partly mediated by desmoglein (Meyer et al., 2004). WNT signals (WNT3a and WNT7a) are capable of holding the dermal papilla in anagen. The transcription factor $\mathrm{Hr}$ is a central, indispensable element that is involved in navigating and coordinating signal transduction at the anagen-catagen conversion period of the hair follicle. Under the influence of BMP4 and 17ß-estradiol, the hair follicle stays in telogen (Botchkarev and Sharov, 2004; Conrad and Paus, 2004). The thickness of the hair shaft is related to the size of the hair bulb, which is dictated by the volume of the hair follicle's mesenchymal component, and the hair length is defined by the duration of anagen (Krause and Foitzik, 2006).

The mechanism of Type III brush hair formation could be partly illustrated by differential proteomics, which is used to screen and identify the differential protein expression from different types or states. In goat, no large-scale proteomics studies have been reported; however, proteomics methods have been used for some small-scale protein characterization investigations (Paredi et al., 2012). No previous reports on differential proteomics related to Type III hair have been published. We first identified differentially expressed proteins between 
Type III and non-Type III brush hair using differential proteomics. This study will provide useful information related to the regulation mechanisms of Type III brush hair in goat.

\section{MATERIAL AND METHODS}

\section{Sample collection}

Four male lambs of Yangtze River Delta white goats, fed the same diet, were obtained from the Haimen Goat Breeding Factory in Jiangsu Province (China); lambs ranged from 6 to 8 months old. Sample goats are shown in Figure 1 and Figure 2. Skin tissues in the cervical carina region where Type III hair and non-Type III hair grows were obtained. Then, the skin tissue samples were stored at $-196^{\circ} \mathrm{C}$.

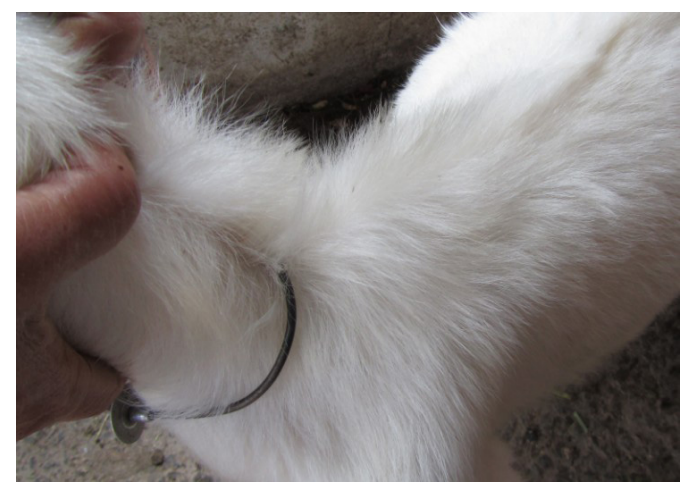

Figure 1. Yangtze River Delta white goat with Type III brush hair.

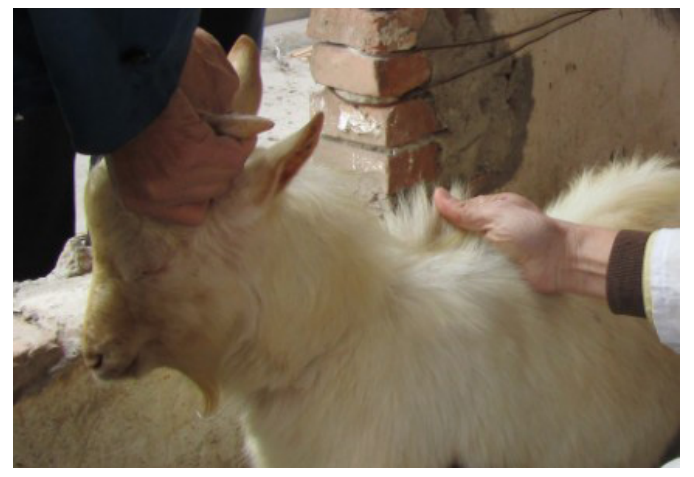

Figure 2. Yangtze River Delta white goat with Non-Type III brush hair.

\section{Extraction and quantification of total protein}

Frozen skin tissue samples from the 2 goats producing Type III hair and 2 goats not producing Type III hair were crushed in mortars containing liquid nitrogen. Then, lysis buffer containing $9 \mathrm{M}$ urea, $1 \%(\mathrm{v} / \mathrm{v})$ immobilized $\mathrm{pH}$ gradient (IPG) buffer (GE Healthcare, Sweden), 1\% (w/v) dithiothreitol (DTT), and 4\% (w/v) 3-[(3-cholesterol ammonia propyl) 
dimethylamine]-1-propyl sulfonic acid (CHAPS) was added. After incubation at $30^{\circ} \mathrm{C}$ for $1 \mathrm{~h}$, the solution was centrifuged at $15000 \mathrm{~g}$ for $15 \mathrm{~min}$ at $20^{\circ} \mathrm{C}$. The supernatant, which was the extracted protein solution, was collected. The skin tissue protein concentrations were measured using the Bradford method (Bradford, 1976).

\section{Isoelectric focusing}

Total protein sample $(1000 \mu \mathrm{g})$ was mixed with fresh rehydration buffer, which contained a trace amount of bromophenol blue, 1\% (v/v) IPG buffer, $9 \mathrm{M}$ urea, 1\% DTT and 4\% $(\mathrm{w} / \mathrm{v})$ CHAPS to a final volume of $450 \mu \mathrm{L}$. The dry strips (GE Healthcare, UK, $24 \mathrm{~cm}, \mathrm{pH}=$ $3-10$, nonlinear) were placed at $20^{\circ} \mathrm{C}$ for $10 \mathrm{~min}$. After the samples were added to the strip holders, which were placed on the IPGphor Isoelectric Focusing System (GE Healthcare, UK), strips were focused for $50 \mu \mathrm{A}$ per strip at $20^{\circ} \mathrm{C}$ using the following program: $50 \mathrm{~V}$ for $12 \mathrm{~h}$, $500 \mathrm{~V}$ for $1 \mathrm{~h}, 1000 \mathrm{~V}$ for $1 \mathrm{~h}$, a gradient increase to $10,000 \mathrm{~V}$ for $1 \mathrm{~h}$, and $10,000 \mathrm{~V}$ for $11 \mathrm{~h}$.

\section{IPG strip equilibration and sodium dodecyl sulfate-polyacrylamide gel electropho- resis (SDS-PAGE)}

After isoelectric focusing, the IPG strips were equilibrated by soaking with $2 \%(\mathrm{w} / \mathrm{v})$ SDS, $1 \%(\mathrm{w} / \mathrm{v})$ DTT, 30\% (v/v) glycerol, $6 \mathrm{M}$ urea, $50 \mathrm{mM}$ Tris-HCl, $\mathrm{pH} 8.8$, and a trace amount of bromophenol blue at room temperature for $15 \mathrm{~min}$. Subsequently, proteins were alkylated with $2 \%(\mathrm{w} / \mathrm{v})$ SDS, $2.5 \%$ iodoacetamide, $30 \%$ (v/v) glycerol, $6 \mathrm{M}$ urea, $50 \mathrm{mM}$

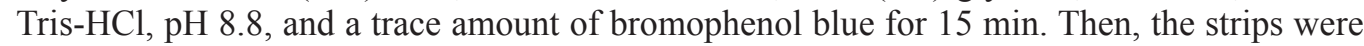
transferred onto the DALT-Six SDS-PAGE Vertical system and developed on 12\% SDS-PAGE gels at $15^{\circ} \mathrm{C}$; electrophoresis was for $45 \mathrm{~min}$ at $100 \mathrm{~V}$, followed by $6-8 \mathrm{~h}$ at $200 \mathrm{~V}$.

\section{Gel visualization and gel analysis}

Gels were visualized after electrophoresis by Coomassie Brilliant Blue stain according to the protocol of Candiano et al. (2004). Gels were fixed with Coomassie stain fixation solution of $10 \%(\mathrm{v} / \mathrm{v})$ trichloroacetic acid for $2 \mathrm{~h}$, followed by staining with Coomassie stain solution containing $10 \%\left(\mathrm{NH}_{4}\right)_{2} \mathrm{SO}_{4}, 10 \% \mathrm{H}_{3} \mathrm{PO}_{4}, 0.1 \%(\mathrm{w} / \mathrm{v})$ Coomassie Brilliant Blue G-250, and $20 \%(\mathrm{v} / \mathrm{v})$ methanol for $12 \mathrm{~h}$. Then, the gels were washed until the spots of interest were clear. Two repeats were performed for each sample (the skin tissues of Type III and non-Type III brush hair goats) for a total of 42 -dimensional electrophoresis (2-DE) maps. Four stained gels were scanned by the ImageScanner Labscan at a resolution of 300 dots per inch. Gel analysis was performed with the PDquest 8.0 software (Bio-Rad, USA). All gel images were processed in 3 steps: spot detection, volumetric quantification, and matching. The different protein concentrations between skin tissues of Type III and non-Type III brush hair goats were determined as fold ratios. Thresholds of fold change more than 2 -fold and $\mathrm{P}<0.05$ were used to select differentially expressed protein spots.

\section{Tryptic in-gel digestion}

The spots were excised from the gel of each sample, washed in acetonitrile (ACN), and dried. Gels were rehydrated with digestion buffer $\left(25 \mathrm{mM} \mathrm{NH}_{4} \mathrm{HCO}_{3}\right)$ containing 0.02 
$\mu \mathrm{g} / \mu \mathrm{L}$ trypsin and incubated overnight at $37^{\circ} \mathrm{C}$. The peptides were extracted with $5 \%(\mathrm{v} / \mathrm{v})$ trifluoroacetic acid (TFA) and $67 \%(\mathrm{v} / \mathrm{v}) \mathrm{ACN}$. This procedure was handled as described by Katayama et al. (2001).

\section{Mass spectrometry (MS) and comparison with databases}

The protein samples were dissolved in $5 \mu \mathrm{L} 0.1 \%(\mathrm{v} / \mathrm{v})$ TFA and then mixed with $\alpha$-cyano-4-hydroxy-trans-cinnamic acid solution at a ratio of 1:1. Mixed solution $(1 \mu \mathrm{L})$ was spotted on a sample target plate. MS detections were performed using an Ultraflex III TOF/ TOF mass spectrometer (Bruker, USA). Data were collected in positive ion mode, and the scan range of mass spectra was from 750 to $3000 \mathrm{Da}$. The MS and MS/MS data were analyzed by Mascot 2.3 (Matrix Science Ltd., UK) after integration. The search parameters were as follows: 1) National Center for Biotechnology Information non-redundant mammals database; 2 ) the digestion enzyme was trypsin; 3 ) the maximum allowed missed cleavage site was $1 ; 4$ ) fixed modifications were carbamidomethyl (C); 5) variable modifications were acetyl (protein N-term), deamidated (NQ), dioxidation (W), and oxidation (M); and 6) the MS tolerance was $100 \mathrm{ppm}$ and MS/MS tolerance was $0.5 \mathrm{Da}$. Proteins were considered to be identified successfully if the confidence interval of the protein score was $95 \%$ or higher.

\section{RESULTS}

\section{Protein mapping of goat skin tissues}

2-DE protein maps of cervical carina skin tissues from both goat groups were established (Figure 3 and Figure 4). Two technical replicates, having good reproducibility, were performed for each of the 2 samples for a total of 42 -DE maps (Figure 5 and Figure 6). Twenty protein spots were upregulated in Type III brush hair goats and 13 protein spots were upregulated in non-Type III brush hair goats, but only 2 protein spots (6809 and 2702) from the Type III hair group and 8 protein spots $(6713,3410,701,3417,8812,3712,3713$, and 4701$)$ from the non-Type III hair group were identified using Ultraflex III TOF/TOF mass spectrometer (Figures 7-16). The criteria to select proteins were that the protein spots in parallel samples of each group had a similar concentration $(88 \pm 10 \%)$ and that the protein expression quantities of parallel samples in the Type III group were both higher or lower than those of the non-Type III group.

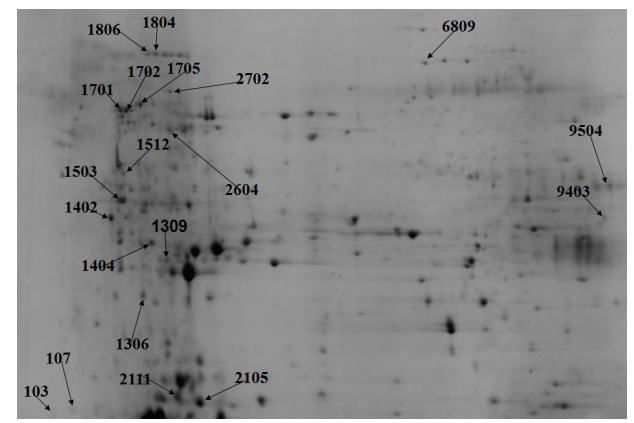

Figure 3. Two-dimensional gel electrophoretic (2-DE) maps of Type III brush hair goat skin tissue in the cervical carina region. The small arrows indicate proteins that were upregulated in the given skin tissues. 


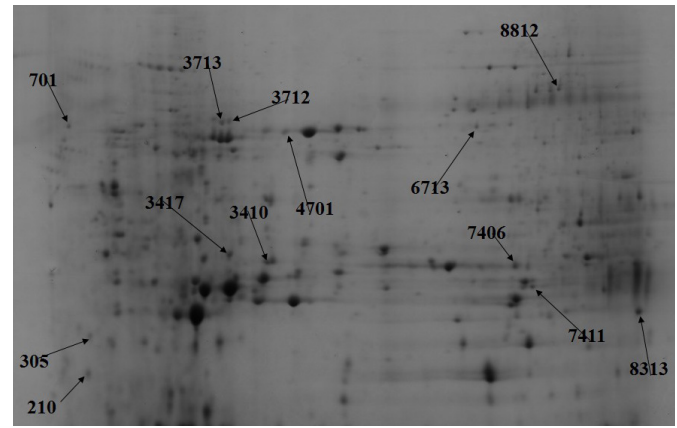

Figure 4. Two-dimensional gel electrophoretic (2-DE) maps of Non-Type III brush hair goat skin tissue in the cervical carina region. The small arrows indicate proteins that were upregulated in the given skin tissues.
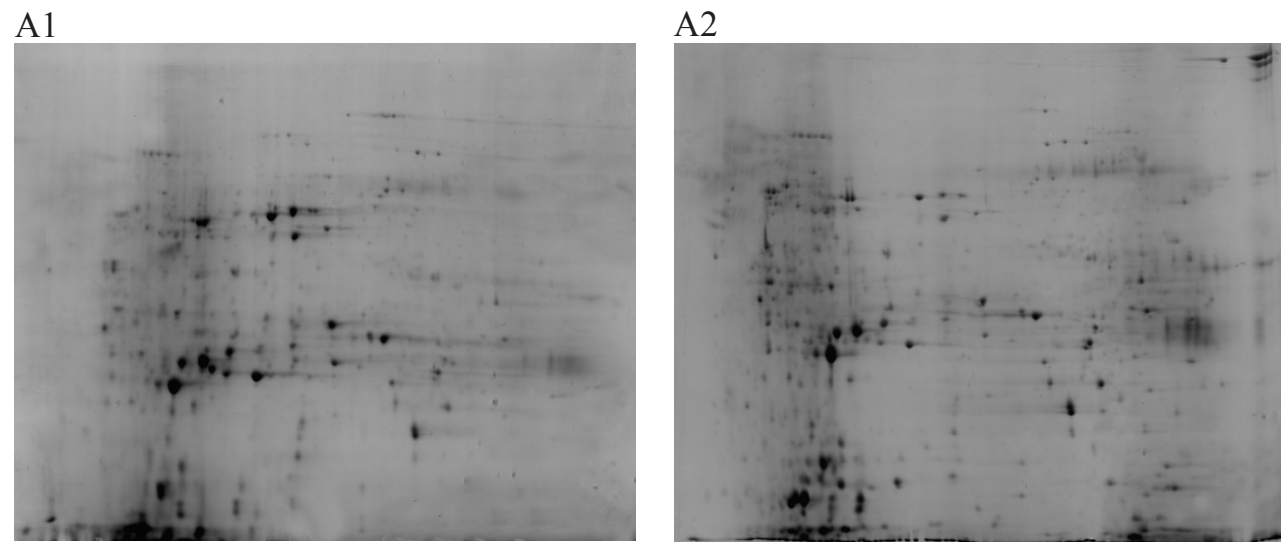

Figure 5. 2-DE maps of repeated samples (A1, A2) of Type III hair goat skin tissue in the cervical carina region.

B1

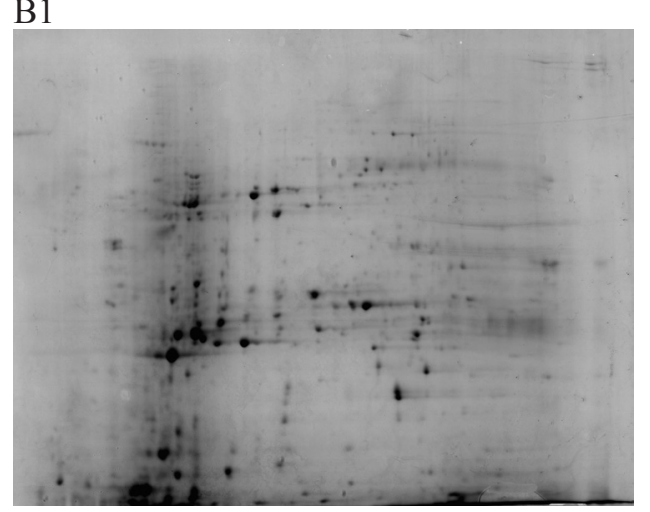

\section{B2}

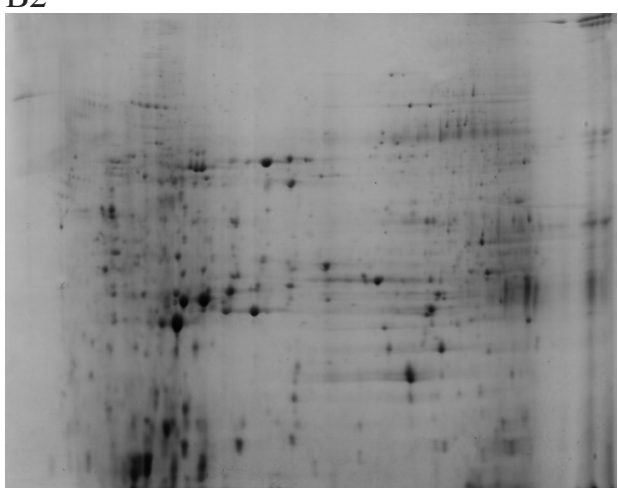

Figure 6. 2-DE maps of repeated samples (B1, B2) of Non-Type III hair goat skin tissue in the cervical carina region. 


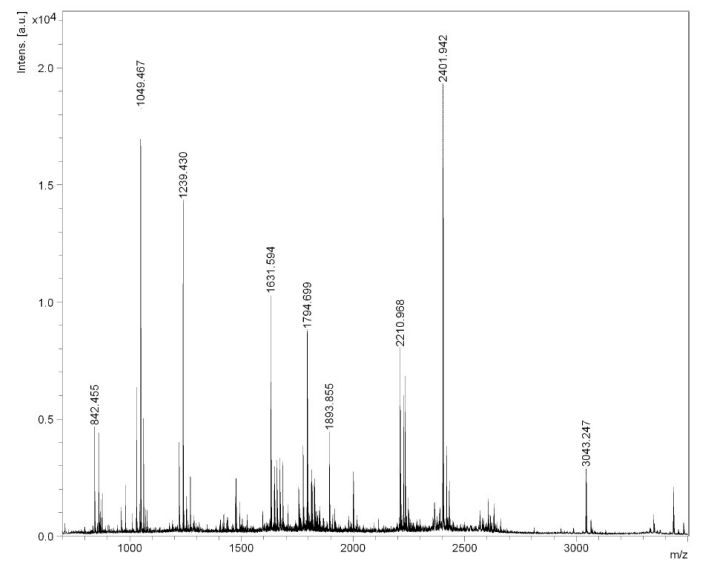

Figure 7. Peptide mass fingerprints of protein spot 6809 in goat skin tissues.

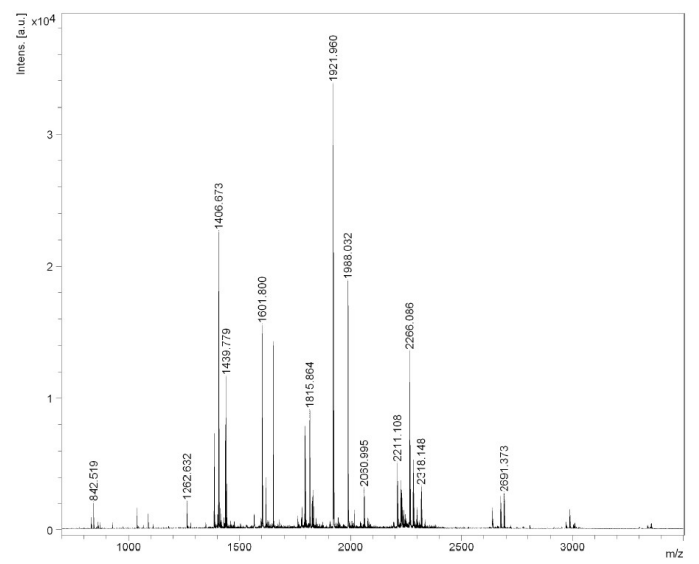

Figure 8. Peptide mass fingerprints of protein spot 2702 in goat skin tissues.

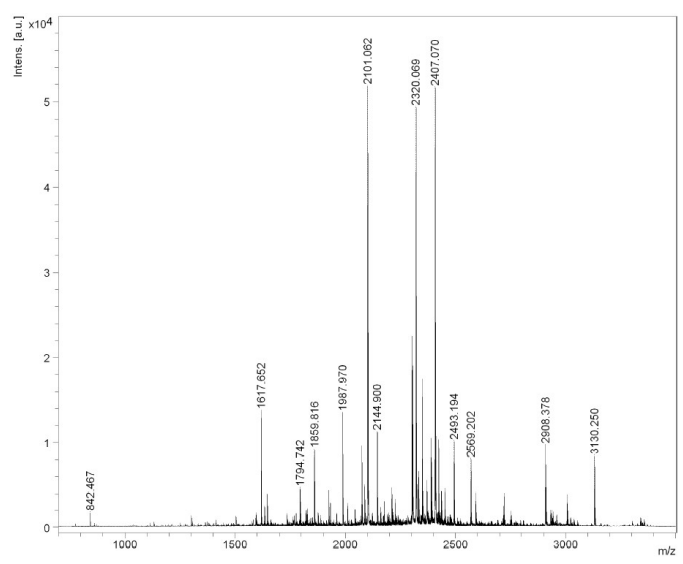

Figure 9. Peptide mass fingerprints of protein spot 8812 in goat skin tissues. 


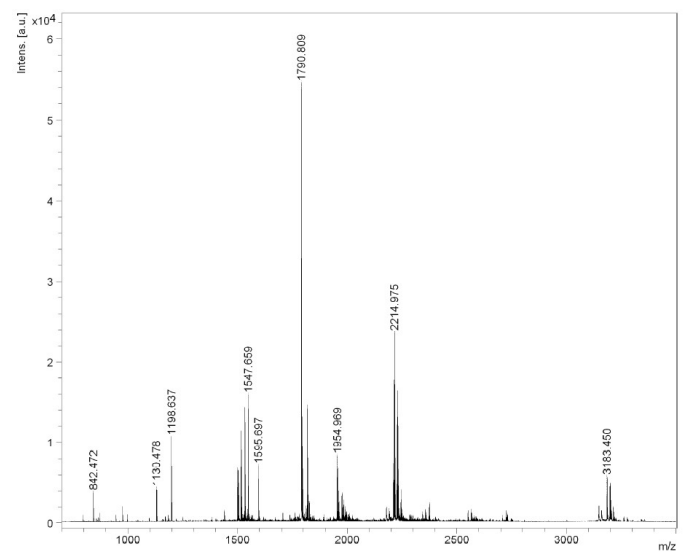

Figure 10. Peptide mass fingerprints of protein spot 3712 in goat skin tissues.

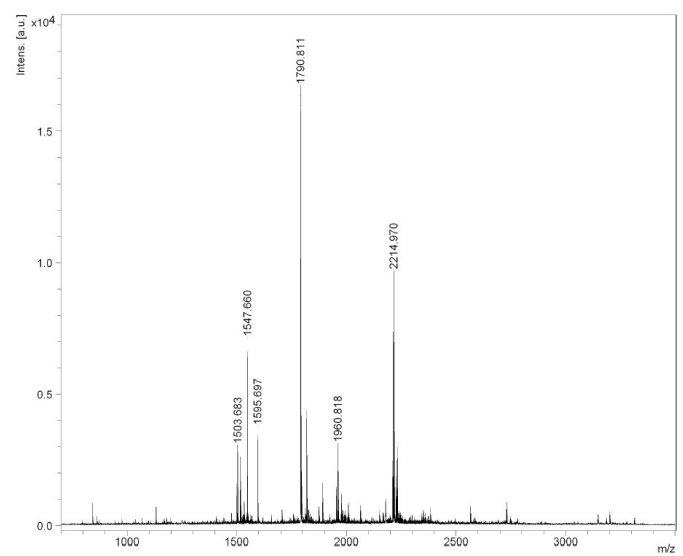

Figure 11. Peptide mass fingerprints of protein spot 3713 in goat skin tissues.

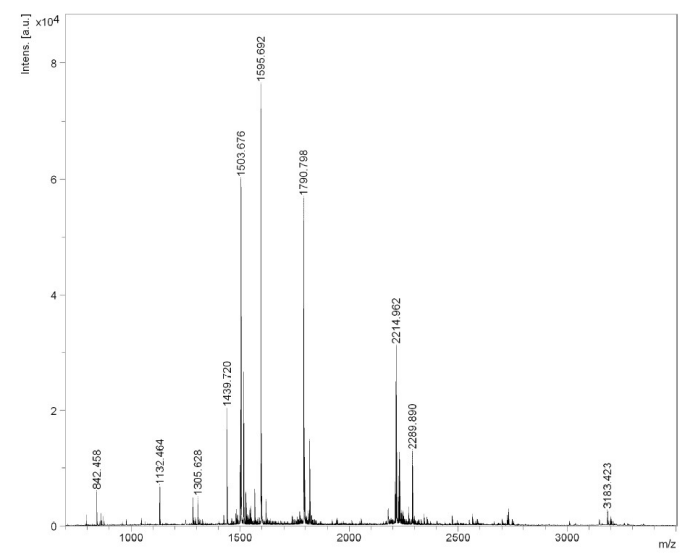

Figure 12. Peptide mass fingerprints of protein spot 3410 in goat skin tissues. 


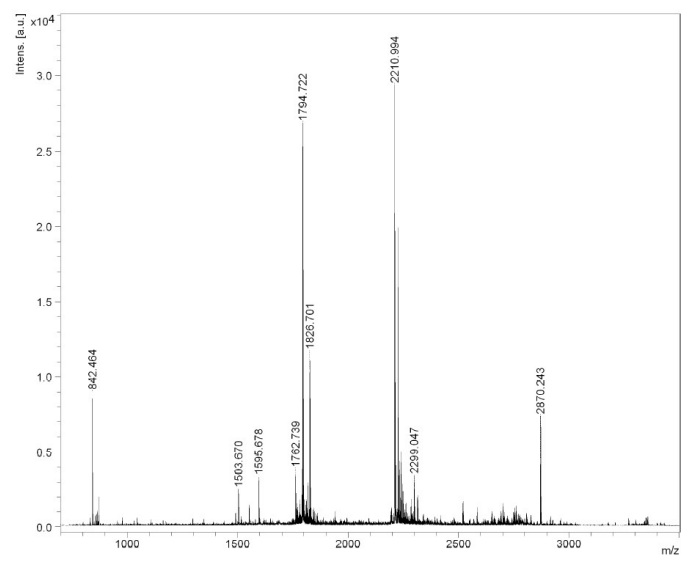

Figure 13. Peptide mass fingerprints of protein spot 701 in goat skin tissues.

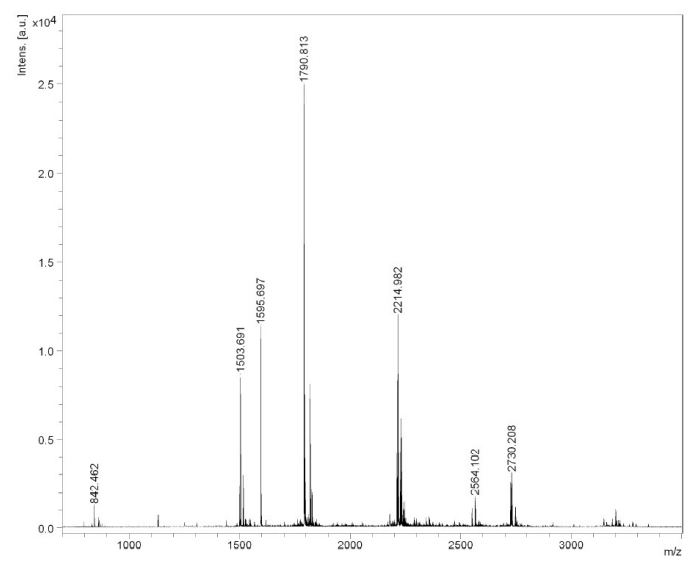

Figure 14. Peptide mass fingerprints of protein spot 3417 in goat skin tissues.

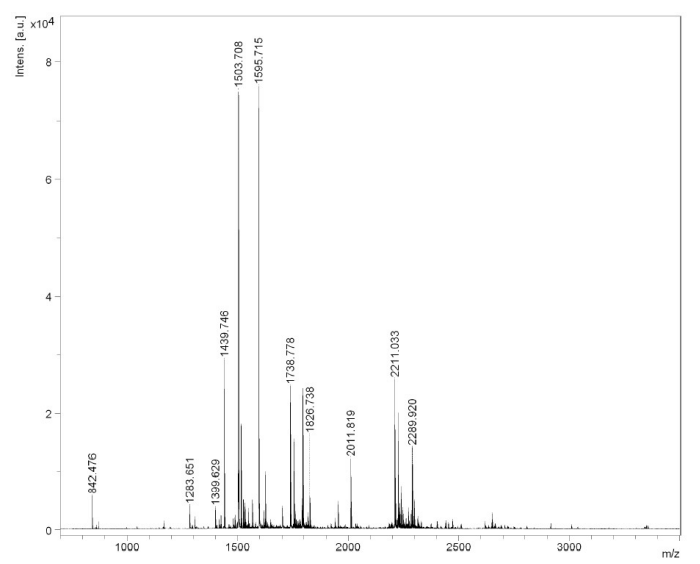

Figure 15. Peptide mass fingerprints of protein spot 4701 in goat skin tissues. 


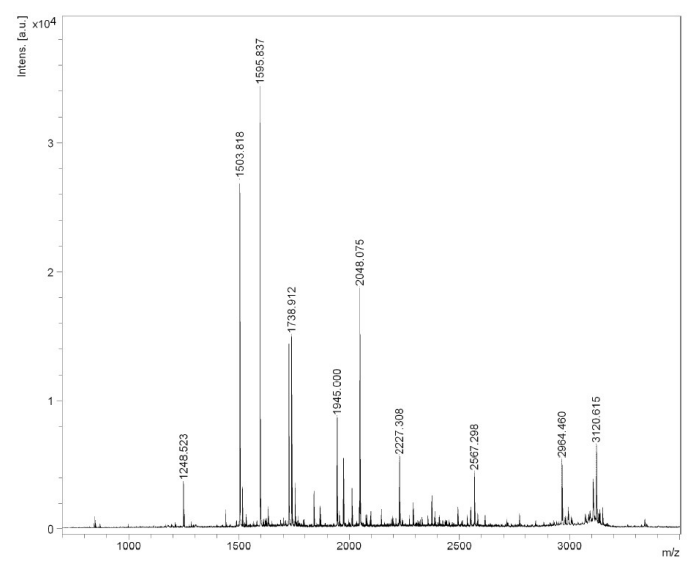

Figure 16. Peptide mass fingerprints of protein spot 6713 in goat skin tissues.

\section{Identification of differentially expressed proteins}

Ten differentially expressed spots were found between Type III hair and non-Type III hair by 2-DE analysis. The complexity of proteomics and the existence of modifications after translation, such as pyrolysis, phosphorylation, glycosylation, and oxidation, were revealed as several protein spots that represented one protein or one protein spot that contained several proteins in the 2-DE protein maps. In this study, protein spots 3410, 701, 3417, 4701, and 6713 represented the same protein, serum albumin precursor, which probably came from the blood accompanied by the skin tissues when sampling. Spots 3712 and 3713 were beta actin. Spot 6809 was fibrinogen beta chain isoform 1, spot 2702 was ATP synthase beta subunit, and spot 8812 was succinyl-CoA:3-ketoacid-coenzyme A transferase 1-mitochondrial-like (SCOT). After the identification of protein types by MS analysis, 4 different proteins were considered as real differentially expressed proteins. Two of the 4 proteins were upregulated in Type III hair, fibrinogen beta chain isoform 1 and ATP synthase beta subunit (Table 1). The other 2 proteins were upregulated in non-Type III hair, SCOT and beta actin (Table 2).

Table 1. Protein spots upregulated in Type III brush hair goat skin tissue by Ultraflex III TOF/TOF analysis.

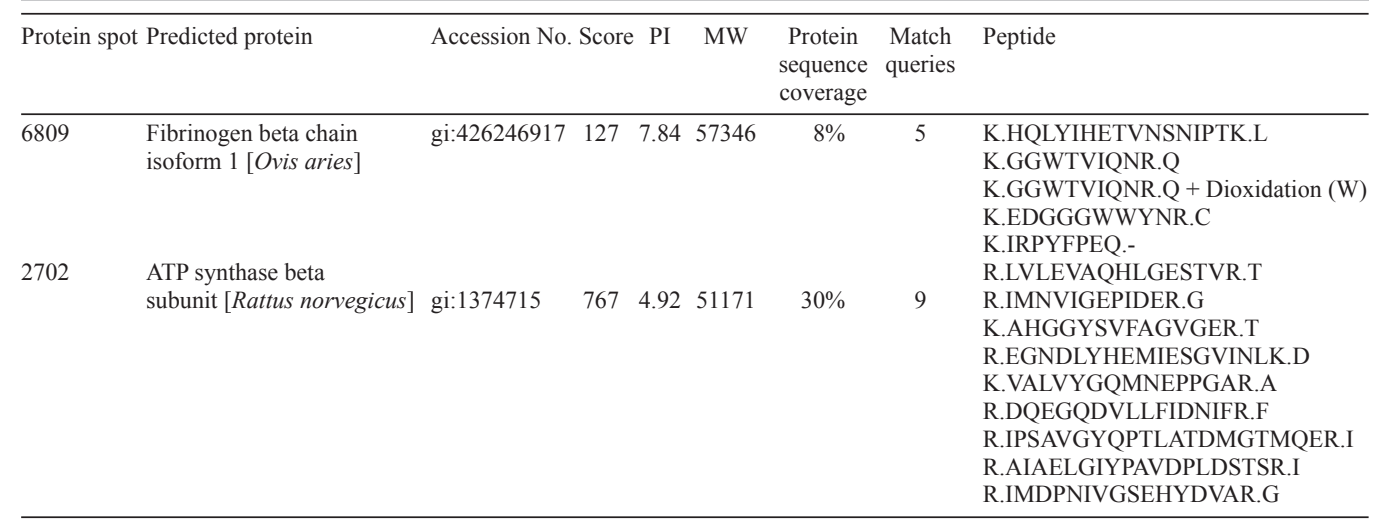

$\mathrm{PI}=$ isoelectric point; $\mathrm{MW}=$ molecular weight. 


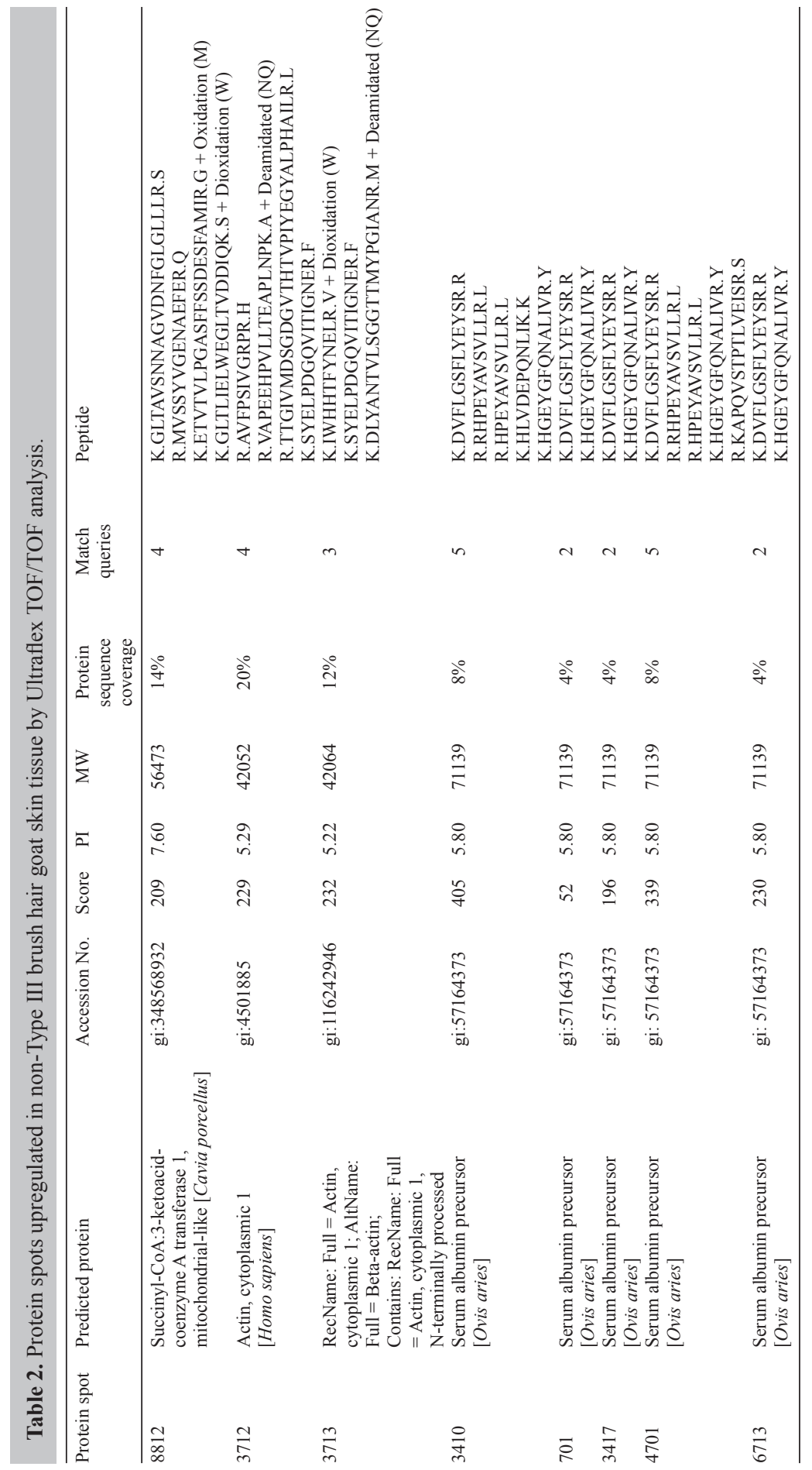


The protein sequence that matched peptide information of spots 6809 and 2702, which were upregulated in Type III hair, is shown in Tables 3 and 4.

Table 3. Matching of protein spot 6809 mass spectrometry data with gi426246917 in database.

\begin{tabular}{lccccccl}
\hline Start-end & Observed & Mr (expt) & Mr $($ calc $)$ & Miss & Score & Expect & Peptide \\
\hline $182-197$ & 1893.8549 & 1892.8476 & 1892.9744 & 0 & 8 & $1 \mathrm{e}+03$ & K.HQLYIHETVNSNIPTK.L \\
$280-288$ & 1030.4680 & 1029.4607 & 1029.5356 & 0 & 21 & 35 & K.GGWTVIQNR.Q \\
$280-288$ & 1062.4568 & 1061.4495 & 1061.5254 & 0 & 17 & 89 & K.GGWTVIQNR.Q + Dioxidation(W) \\
$430-439$ & 1239.4297 & 1238.4224 & 1238.5105 & 0 & 59 & 0.0013 & K.EDGGGWWYNR.C \\
$487-494$ & 1049.4673 & 1048.4600 & 1048.5342 & 0 & 39 & 0.74 & K.IRPYFPEQ.- \\
\hline
\end{tabular}

$\mathrm{Mr}(\mathrm{expt})=$ experimental molecular; $\mathrm{Mr}($ calc $)=$ calculative molecular.

Table 4. Matching of protein spot 2702 mass spectrometry data with gi1374715 in database.

\begin{tabular}{lccccrll}
\hline Start-end & Observed & Mr (expt) & Mr (calc) & Miss & Score & Expect & Peptide \\
\hline $41-55$ & 1650.9070 & 1649.8997 & 1649.9101 & 0 & 93 & $2.8 \mathrm{e}-06$ & R.LVLEVAQHLGESTVR.T \\
$90-101$ & 1385.6953 & 1384.6880 & 1384.7020 & 0 & 74 & 0.00025 & R.IMNVIGEPIDER.G \\
$172-185$ & 1406.6731 & 1405.6658 & 1405.6739 & 0 & 109 & $7.7 \mathrm{e}-08$ & K.AHGGYSVFAGVGER.T \\
$188-205$ & 2060.9954 & 2059.9881 & 2059.9884 & 0 & 45 & 0.17 & R.EGNDLYHEMIESGVINLK.D \\
$211-225$ & 1601.7996 & 1600.7923 & 1600.8031 & 0 & 95 & $2.1 \mathrm{e}-06$ & K.VALVYGQMNEPPGAR.A \\
$241-256$ & 1921.9597 & 1920.9524 & 1920.9581 & 0 & 157 & $1.3 \mathrm{e}-12$ & R.DQEGQDVLLFIDNIFR.F \\
$271-291$ & 2266.0859 & 2265.0786 & 2265.0770 & 0 & 36 & 1.3 & R.IPSAVGYQPTLATDMGTMQER.I \\
$334-352$ & 1988.0325 & 1987.0252 & 1987.0262 & 0 & 60 & 0.0053 & R.AIAELGIYPAVDPLDSTSR.I \\
$353-368$ & 1815.8639 & 1814.8566 & 1814.8621 & 0 & 98 & $9.3 \mathrm{e}-07$ & R.IMDPNIVGSEHYDVAR.G \\
\hline
\end{tabular}

\section{DISCUSSION}

Goat hair growth is mainly based on the occurrence and development of hair follicles. In this study, fibrinogen beta chain isoform 1 and ATP synthase beta subunit were involved in Type III brush hair formation in goat. The other 2 differentially expressed proteins, SCOT and beta actin, probably played pivotal roles in forming non-Type III brush hair.

\section{Relationship between fibrinogen beta chain isoform 1 and hair follicle growth}

Fibrinogen beta is an enzyme that limits the synthesis rate of fibrinogen, and studies related to fibrinogen level regulation have focused on the related gene, fibrinogen beta (Roy et al., 1990), in which the promoter region contained some polymorphisms, including $-148 \mathrm{C} / \mathrm{T}$, $-455 \mathrm{G} / \mathrm{A}$, and-854 G/A, that are related to higher plasma fibrinogen levels (Green, 2001; Brull et al., 2002). Rallidis et al. (2010) reported that plasma fibrinogen levels can affect platelet aggregation, endothelial cell injury, and blood viscosity. Fibrinogen cleavage products were the mitogens for various kinds of cells, such as mesothelial cells, fibroblasts, and endothelial cells (Herrick et al., 1999). Hair follicles, interestingly, are connected by a network of blood capillaries, which can transport nutrients to the hair bulb. Fibrinogen beta chain isoform 1 may stimulate the formation of blood capillaries around the hair follicles by influencing blood viscosity. This connection supports the basic knowledge that rich support of nutrition could bring more solid parts in hair, aiding the cortex formation.

The difference between Type III hair and non-Type III hair is whether the medulla exists at the top of the hair. Type III hair only had a cuticle and the major solid part of the hair shaft, the cortex, while the non-Type III hair had medulla in the center of the hair shaft. The 
Type III hair tended to have relatively more cortex than the non-Type III hair. Fibrinogen belongs to the adhesion protein family (Sun and Hu, 2004); perhaps it has a vital role in cell adhesion, cell proliferation, and other physiological functions of the cortex. This higher expressed differential protein in Type III hair was more conducive to forming no medullary segment.

\section{Relationship between ATP synthase beta subunit and hair follicle growth}

The ATP synthase, namely $\mathrm{F}_{0} \mathrm{~F}_{1}$-ATP synthase, is an enzyme that catalyzes and hydrolyzes ATP. The 3 catalytic sites for ATP synthesis and hydrolysis are situated primarily on the $\beta$ subunit at $\alpha / \beta$ interfaces (Zhou et al., 1996). The production of ATP on the surface of certain cells is important for cell proliferation (Arakaki et al., 2003). ATP synthase $\beta$ could affect ATP synthesis and hydrolysis through the 3 catalytic sites and then offer energy for hair follicle growth. Besides, it could influence the proliferation of hair follicle growth-associated cells such as keratinocytes on the corresponding cell surface. The higher content of ATP synthase $\beta$ in the skin tissue of Type III hair compared to non-Type III hair suggests that the formation of more solid parts in Type-III hair needs a higher content of ATP. The hair shaft cell differentiation was determined by the cell division speed of the hair bulb, the keratin synthesis ability, and the competition for keratin synthesis precursors. At one moment, the hair follicle had the maximum capacity of keratin synthesis. When the keratin synthetic quantity could not meet the demand quantity of cortex cells, the medulla appeared. Otherwise, the excess keratin synthesis would lead to the appearance of a deputy cortex. Hence, the keratin synthesis ability was a critical factor in determining the formation of a medulla or deputy cortex (Deng, 1997). We suspect that the hair follicles of group Type III hair reached a maximum capacity of keratin synthesis when there was excess energy and then formed the deputy cortex, which was possible because of the increasing cortex content. The greater the proportion of cortex was, the thinner the wool would be. The segment without a medulla was very thin on the top of the Type III hair; this result confirmed the above suspicions.

\section{Relationship between SCOT and hair follicle growth}

SCOT (OXCT) is vital to the utilization of ketone bodies as a mitochondrial homodimer and is an important vector of energy transport from the liver to other organs and tissues; it also catalyzes acetoacetate to acetoacetyl-CoA (Fukao et al., 2000). Then, acetoacetyl-CoA is turned into acetyl-CoA, which is mainly utilized in the citric acid cycle. Many studies have focused on SCOT. cDNA of SCOT-t, separated from human testis, was particularly expressed in late haploid male germ cells. The SCOT-t protein was discovered at the middle piece of ejaculated spermatozoa where mitochondria exist, demonstrating that the SCOT-t protein has a vital role in spermatogenesis and offers energy to the semen (Tanaka et al., 2001). The above-mentioned studies demonstrated that SCOT has an important role in testis, which is highly relevant to androgens. Androgens affect some features of human skin, including hair growth, sebaceous gland differentiation, and wound healing (Zouboulis et al., 2007). Androgens stimulate hair growth in some regions, leading to males having dense hair on the chest and face (Hamilton, 1958). In contrast, on specific scalp areas, androgens had the opposite influence and lead to balding (Hamilton, 1951). Therefore, androgens exhibit a biological paradox to hair follicles.

Androgens act after binding to the androgen receptor (AR). The AR, a steroid hor- 
mone nuclear receptor super family member, exists in the dermal papilla and in most parts of the hair follicle (Sawaya and Price, 1997). However, the hair bulb is considered as the main action site of androgens. When the matrix cells in hair bulb differentiate into the hair root, androgens affected the formation of the medulla and the reduction of cortex.

Type III hairs were only produced on $5-8 \%$ of 6 - to 8 -month-old male lambs. Female goats and castrated goats do not produce Type III hairs. The androgens of these goats were obviously different. A previous study also proved that the formation of Type III hair was related to the androgen level $(\mathrm{Li}, 2013)$. The higher content of SCOT in the skin tissue of Type III hair exposed to high levels of androgens would lead to the formation of a medullary segment.

The coding gene of SCOT, OXCT, was also related to cell growth rate (Zhang et al., 1990). One scholar researched the influence of $O X C T 1$ expression on cell cycles, and the result showed that overexpression of OXCT1 could promote DNA synthesis; therefore, OXCT1 may promote cell proliferation and protein synthesis (Zhang, 2007). In this study, the higher expression of SCOT in non-Type III hair demonstrated that SCOT may have a positive effect on the synthesis of the high content of proteins in the medulla including trichohyalin and involucrin (Alibardi, 2012) and keratins such as K5, K14, K17, and K25 (Langbein et al., 2010). Besides the androgen aspect, SCOT could influence hair follicle growth from the cell proliferation aspect, leading to the formation of the medulla segment.

\section{Relationship between beta actin and hair follicle growth}

Beta actin (gene name $A C T B$ ) belongs to the cytoskeletal filament family. It is a non-muscle cytoskeletal actin. Beta actin can be one of the most abundant and highly conserved proteins, and it acts in vital roles in gene expression, wound healing, cell division, cell migration, immune response, and embryonic development (Guo et al., 2013). For instance, beta actin polymerization can push the membrane ahead by providing the protrusive forces to drive cell migration at the leading edge (Popow et al., 2006). Keratins, the pivotal proteins in hair fibers, were the largest and most complex group of intermediate filament proteins that constitute important parts of the cytoskeleton. As components of the cytoskeleton, beta actin and keratins interact and jointly promote the important mechanical properties of hair follicle-associated cells such as cellular shape, cellular division, and intracellular transport.

The medulla layer is composed of irregular and thin-walled keratinocytes, and it showed a net-like structure from a cross-sectional view. The connection between medulla cells is poor. On the one hand, the differentiation of medullary cells occurs with a peculiar process of granule accumulation, granule fusion, and, eventually, margination that results in the formation of corneous trabeculae among hollow spaces (De Cássia Comis Wagner et al., 2007; Alibardi, 2012). As a member of the cytoskeletal filament family, beta actin could maintain the morphological structure of corneous trabeculae, which helps maintain the medulla layer. On the other hand, cytoskeletal filaments act as a component of the membrane skeleton under the plasma membrane; these filaments restrict the movement of membrane proteins (Liu, 2009). Beta actin may restrict the movement of membrane proteins in medulla-layer keratinocytes; this makes the connection between medulla cells not close and reduced the elasticity and strength of wool. The higher expression of beta actin in non-Type III hair suggested that beta actin may play an important role in the formation of the medullary space. 


\section{CONCLUSIONS}

We explored the Type III brush hair formation mechanisms using comparative proteomics. Four differentially expressed proteins that were involved in Type III hair development provide a new aspect to further study of the formation mechanisms of the high-quality brush hair in this goat. Furthermore, the data from this study may be useful to increase the quantity and quality of Type III hair.

\section{ACKNOWLEDGMENTS}

Research supported by research grant \#2010CXJ049 from the Science and Technology Innovation Project of Yangzhou University and the Priority Academic Program Development (PAPD) of Jiangsu Higher Education Institutions.

\section{REFERENCES}

Alibardi L (2012). Ultrastructural immunolocalization of involucrin in the medulla and inner root sheath of the human hair. Ann. Anat. 194: 345-350.

Arakaki N, Nagao T, Niki R, Toyofuku A, et al. (2003). Possible role of cell surface $\mathrm{H}^{+}$-ATP synthase in the extracellular ATP synthesis and proliferation of human umbilical vein endothelial cells. Mol. Cancer Res. 1: 931-939.

Botchkarev VA and Sharov AA (2004). BMP signaling in the control of skin development and hair follicle growth. Differentiation 72: 512-526.

Bradford MM (1976). A rapid and sensitive method for the quantitation of microgram quantities of protein utilizing the principle of protein-dye binding. Anal. Biochem. 72: 248-254.

Brull DJ, Dhamrait S, Moulding R, Rumley A, et al. (2002). The effect of fibrinogen genotype on fibrinogen levels after strenuous physical exercise. Thromb. Haemost. 87: 37-41.

Candiano G, Bruschi M, Musante L, Santucci L, et al. (2004). Blue silver: a very sensitive colloidal Coomassie G-250 staining for proteome analysis. Electrophoresis 25: 1327-1333.

Conrad F and Paus R (2004). The role of estrogens in hair biology. J. Dtsch. Dermatol. Ges. 2: 412-423.

De Cássia Comis Wagner R, Kiyohara PK, Silveira M and Joekes I (2007). Electron microscopic observations of human hair medulla. J. Microsc. 226: 54-63.

Deng K (1997). The theoretical models of the formation of wool hair follicle and the synthesis of wool fibre (in Chinese). China Herbivores 1: 43-45.

Fukao T, Mitchell GA, Song XQ, Nakamura H, et al. (2000). Succinyl-CoA:3-ketoacid CoA transferase (SCOT): cloning of the human SCOT gene, tertiary structural modeling of the human SCOT monomer, and characterization of three pathogenic mutations. Genomics 68: 144-151.

Green FR (2001). Fibrinogen polymorphisms and atherothrombotic disease. Ann. N. Y. Acad. Sci. 936: 549-559.

Guo C, Liu S, Wang J, Sun MZ, et al. (2013). ACTB in cancer. Clin. Chim. Acta 417: 39-44.

Hamilton JB (1951). Patterned loss of hair in man; types and incidence. Ann. N. Y. Acad. Sci. 53: 708-728.

Hamilton JB (1958). Age, sex and genetic factors in the regulation of hair growth in man: a comparison of Caucasian and Japanese populations. In: The biology of hair growth (Montagna W and Ellis RA, eds.). Academic Press, New York, 399-433.

Herrick S, Blanc-Brude O, Gray A and Laurent G (1999). Fibrinogen. Int. J. Biochem. Cell Biol. 31: 741-746.

Katayama H, Nagasu T and Oda Y (2001). Improvement of in-gel digestion protocol for peptide mass fingerprinting by matrix-assisted laser desorption/ionization time-of-flight mass spectrometry. Rapid Commun. Mass Spectrom. 15: 1416-1421.

Krause K and Foitzik K (2006). Biology of the hair follicle: the basics. Semin. Cutan. Med. Surg. 25: 2-10.

Langbein L, Yoshida H, Praetzel-Wunder S, Parry DA, et al. (2010). The keratins of the human beard hair medulla: the riddle in the middle. J. Invest. Dermatol. 130: 55-73.

Li W (2013). Study on differential expression of genes influencing the formation of high quality brush hair in Yangtze River Delta white goat. Master's thesis, Yangzhou University, Yangzhou.

Li Y, Li W, Zhang J, Ji D, et al. (2013). Identification of genes influencing formation of the Type III Brush Hair in Yangtze 
River Delta white goats by differential display of mRNA. Gene 526: 205-209.

Liu Y (2009). Associativity study between actin degradation regularity and the estimation of postmortem interval. Doctoral thesis, Shanxi Medical University, Taiyuan.

Meyer B, Bazzi H, Zidek V, Musilova A, et al. (2004). A spontaneous mutation in the desmoglein 4 gene underlies hypotrichosis in a new lanceolate hair rat model. Differentiation 72: 541-547.

Paredi G, Raboni S, Bendixen E, de Almeida AM, et al. (2012). "Muscle to meat" molecular events and technological transformations: the proteomics insight. J. Proteomics 75: 4275-4289.

Paus R and Foitzik K (2004). In search of the "hair cycle clock": a guided tour. Differentiation 72: 489-511.

Popow A, Nowak D and Malicka-Blaszkiewicz M (2006). Actin cytoskeleton and beta-actin expression in correlation with higher invasiveness of selected hepatoma Morris 5123 cells. J. Physiol. Pharmacol. 57: 111-123.

Rallidis LS, Gialeraki A, Fountoulaki K, Politou M, et al. (2010). G-455A polymorphism of $\beta$-fibrinogen gene and the risk of premature myocardial infarction in Greece. Thromb. Res. 125: 34-37.

Roy SN, Mukhopadhyay G and Redman CM (1990). Regulation of fibrinogen assembly: transfection of Hep G2 cells with B beta cDNA specifically enhances synthesis of the three component chains of fibrinogen. J. Biol. Chem. 265: 6389-6393.

Sawaya ME and Price VH (1997). Different levels of $5 \alpha$-reductase type I and II, aromatase, and the androgen receptor in human hair follicles of women and men with androgenetic alopecia. J. Invest. Dermatol. 109: 296-300.

Schneider MR, Schmidt-Ullrich R and Paus R (2009). The hair follicle as a dynamic miniorgan. Curr. Biol. 19: R132-R142.

Sun Q and Hu D (2004). The change of plasma fibrinogen contents in malignant tumor patients (in Chinese). J. Zhengzhou University (medical science) 39: 841-843.

Tanaka H, Kohroki J, Iguchi N, Onishi M, et al. (2001). Cloning and characterization of a human orthologue of testisspecific succinyl CoA: 3-oxo acid CoA transferase (Scot-t) cDNA. Mol. Hum. Reprod. 8: 16-23.

Zhang WW, Lindahl R and Churchill P (1990). Regulation of succinyl coenzyme A:acetoacetyl coenzyme A transferase in rat hepatoma cell lines. Cancer Res. 50: 5858-5862.

Zhang Q (2007). Differential proteomics identification of the myogenesis in layer and broiler chicken. Master's thesis, Peking Union Medical College, Beijing.

Zhou Y, Duncan TM, Bulygin VV, Hutcheon ML, et al. (1996). ATP hydrolysis by membrane-bound Escherichia coli $\mathrm{F}_{0} \mathrm{~F}_{1}$ causes rotation of the $\gamma$ subunit relative to the $\beta$ subunits. Biochim. Biophys. Acta 1275: 96-100.

Zouboulis CC, Chen WC, Thornton MJ, Qin K, et al. (2007). Sexual hormones in human skin. Horm. Metab. Res. 39: 85-95. 